\title{
COMPARAÇÃO DO EFEITO ELETROQUÍMICO DO BENZOTRIAZOL E DO NITRATO DE SÓDIO EM MEIO ÁCIDO NA CORROSÃO DO AÇO INOXIDÁVEL ABNT 304
}

\section{COMPARISON OF THE ELECTROCHEMICAL EFFECT OF BENZOTRIAZOLE AND SODIUM NITRITE IN ACID CORROSION IN STAINLESS STEEL AISI 304}

\section{Jaqueline Nascimento da Silva ${ }^{1}$; Luis Fernando dos Santos ${ }^{2}$; Patricia Alexandra Antunes ${ }^{3}$}

\author{
1, 2, 3 Faculdade de Ciências, Letras e Educação de Presidente Prudente - FACLEPP - \\ Universidade do Oeste Paulista - Unoeste \\ e-mail: jaqueline@unoeste.br ${ }^{1}$; santos.Ifq@gmail.com ${ }^{2}$; antunes@unoeste.br ${ }^{3}$
}

RESUMO - Aços inoxidáveis vêm ganhando grande utilidade em virtude de suas características de excelente resistência à corrosão, dentre outras características. As mais variadas formas de utilização os expõem a diversas situações de temperatura, pressão e contato com variadas substâncias, ocasionando a corrosão mesmo apresentando uma boa resistência. O objetivo do trabalho foi estudar a ação eletroquímica do benzotriazol e nitrato de sódio na corrosão do aço inoxidável ABNT 304 em ácido clorídrico. Empregou-se medidas de potencial de circuito aberto, curva de polarização e análise óptica a temperatura de $24 \pm 1$ 으. Os resultados da análise óptica mostraram efeito corrosivo no aço inoxidável ABNT 304 na presença de $\mathrm{HCl}$ e nitrato de sódio e menor corrosão na presença do benzotriazol. Medidas de potencial de circuito aberto, para o benzotriazol, mostraram proteção inibidora pouco representativa e o nitrato de sódio funcionou como catalisador. A curva de polarização confirma os resultados anteriores.

Palavras-chave: aço inoxidável ABNT 304; corrosão; inibidores; técnicas eletroanalíticas; eletroquímica.

ABSTRACT - Stainless steels have gained great utility because of their characteristics of excellent resistance to corrosion, among other characteristics. The most varied uses expose them to various situations of temperature, pressure and contact with various substances, causing corrosion even with good resistance. The objective of this work was to study the electrochemical action of benzotriazole and sodium nitrate in the corrosion of stainless steel ABNT 304 in hydrochloric acid. Measurements of open circuit potential, polarization curve and optical analysis were used at a temperature of $24 \pm 1{ }^{\circ} \mathrm{C}$. The results of the optical analysis showed a corrosive effect on stainless steel ABNT 304 in the presence of $\mathrm{HCl}$ and sodium nitrate and less corrosion in the presence of benzotriazole. Open circuit potential measurements for benzotriazole showed little representative inhibitory protection and sodium nitrate functioned as a catalyst. The polarization curve confirms the previous results.

Recebido em: 27/05/2018

Revisado em: 21/08/2018

Aprovado em: 22/08/2018
Keywords: stainless steel AISI 304; corrosion; inhibitors; electroanalytical techniques; electrochemistry. 


\section{INTRODUÇÃO}

Os aços inoxidáveis são muito utilizados em virtude de suas características de excelente resistência à corrosão, resistência mecânica elevada, boa conformação mecânica, facilidade de reciclagem, versatilidade, forte apelo estético, higiene/assepsia, facilidade de limpeza e longo ciclo de vida. Em função destes atributos, os aços inoxidáveis são utilizados como produtos diversos na área médica, eletrodomésticos, fachadas, esquadrias, sistema de ancoragem de pedras, conexões, mobiliário, mobiliário urbano, grades e portões, pisos, decoração de interiores, escadas, gradis e corrimões, monumentos e esculturas, dentre uma infinidade de outras aplicações que se relacionam principalmente com sua propriedade mais destacável, a elevada resistência à corrosão (SANTOS, 2007).

A utilização dos aços inoxidáveis apresenta uma característica muito marcante: a exposição a diversas situações de temperatura, pressão e contato com as mais variadas substâncias. Devido a esta característica de uso, a ocorrência de corrosão nesses aços, mesmo eles apresentando uma boa resistência, é muito comum. A corrosão está frequentemente relacionada às mais diversas atividades da indústria química, petroquímica, petrolífera, naval, automobilística, construção civil, odontologia, medicina e em monumentos históricos (GENTIL, 2003).

Uma das alternativas para controlar a corrosão é o emprego de inibidores de corrosão. Inibidor é uma substância ou mistura de substância que, quando presentes em concentrações adequadas, no meio corrosivo, reduz ou elimina a corrosão, (SIMÕES; CASTRO; ANDRADE, 2010). Há diferentes tipos de inibidores, sendo eles divididos em orgânicos e inorgânicos.

Os inibidores orgânicos, também chamados de inibidores de adsorção, funcionam como películas protetoras.
Algumas substâncias têm a capacidade de formar películas sobre as áreas anódicas e catódicas, interferindo com a ação eletroquímica. Neste grupo, estão incluídas substâncias orgânicas com grupos fortemente polares que dão lugar à formação de películas de adsorção (GENTIL, 2003).

Já os inibidores inorgânicos podem ser classificados em inibidores anódicos e catódicos. Inibidores anódicos atuam repelindo reações anódicas, ou seja, retardam ou impedem a reação do ânodo. Inibidores catódicos são substâncias que fornecem íons metálicos capazes de reagir com a alcalinidade catódica, produzindo compostos insolúveis (GENTIL, 2003).

Diversos são os compostos que atuam como inibidores de corrosão, e entre eles tem-se o benzotriazol que apresenta fórmula molecular $\mathrm{C}_{6} \mathrm{H}_{5} \mathrm{~N}_{3}$. O benzotriazol é um importante inibidor de corrosão para cobre. Nos últimos anos, vem-se aumentando o número de trabalhos empregando o benzotriazol como inibidor para ligas de cobre, como latão e ligas cuproníquel. Diversos trabalhos mostram a eficiência do benzotriazol, tanto para o ferro e ligas ferrosas, como para o aço inoxidável em meio ácido (TUSSOLINI et al., 2007).

Com relação aos inibidores inorgânicos: nitritos, cromatos, molibdatos, por exemplo, favorecem uma rápida oxidação do metal, formando uma camada de óxido que ocupa o local dos sítios ativos de oxidação, diminuindo, consideravelmente, os processos anódicos. Porém muitos dos inibidores comumente utilizados na indústria são tóxicos e podem causar sérios danos à saúde. Em detrimento disto, os inibidores orgânicos vêm ganhando espaço no mercado industrial (VIOMAR et al., 2010).

O aço inoxidável tipo ABNT 304 não resiste ao ácido clorídrico, ácido sulfúrico diluído e a meios de cloretos e haletos, como, por exemplo, a água do mar (CHIVERINI, 1996). É classificado como um aço austenítico não magnético. 
Devido à problemática envolvida, este trabalho tem como objetivo estudar o comportamento eletroquímico do benzotriazol e do nitrato de sódio na corrosão do aço inoxidável ABNT 304 em presença de ácido clorídrico.

\section{MATERIAL E MÉTODOS}

A eficiência dos inibidores, nitrato de sódio e benzotriazol, foram avaliados através de técnicas eletroanalíticas: curva de polarização e potencial de circuito aberto. As soluções foram preparadas com água pura e os reagentes de grau analítico PA. O eletrodo de trabalho utilizado para a realização dos experimentos foi o aço inoxidável ABNT 304 (na ausência e presença de inibidores). O contra eletrodo e o eletrodo de referência foram platina e eletrodo de calomelano saturado (ECS), respectivamente.

Os experimentos foram realizados em temperatura de $24 \pm 1 \stackrel{\circ}{ } \mathrm{C}$, com concentração de ácido clorídrico de $4 \mathrm{~mol} \mathrm{~L}^{-1}$. As placas utilizadas como eletrodo de trabalho (ABNT 304) e para a obtenção das imagens óticas foram previamente limpas com banho em solução de acetona e, posteriormente, mergulhadas na solução de ácido clorídrico por 90 minutos na presença e na ausência dos inibidores benzotriazol e nitrato de sódio. A concentração dos inibidores foi mantida em $10^{-2} \mathrm{~mol} \mathrm{~L}^{-1}$.

As medidas eletroquímicas foram realizadas em um Potenciostato Autolab PGSTAT $128 \mathrm{~N}$ acoplado com eletrodo de $\mathrm{Hg} / \mathrm{Hg}_{2} \mathrm{Cl}_{2} / \mathrm{KCl}$ (sat.) e eletrodo de platina (eletrodo auxiliar). As placas de aço inoxidável ABNT 304 foram revestidas com resina poliuretano, deixando apenas um orifício circular para o contato do aço com o ácido clorídrico e inibidores. As micrografias foram realizadas com um microscópio óptico Olympus FSX100, com capacidade de aumento de 100x.

\section{RESULTADOS E DISCUSSÃO}

As imagens óticas foram obtidas com um aumento de 100x e são apresentadas na Figura 1.

Figura 1. Microscopia óptica do aço inoxidável ABNT 304

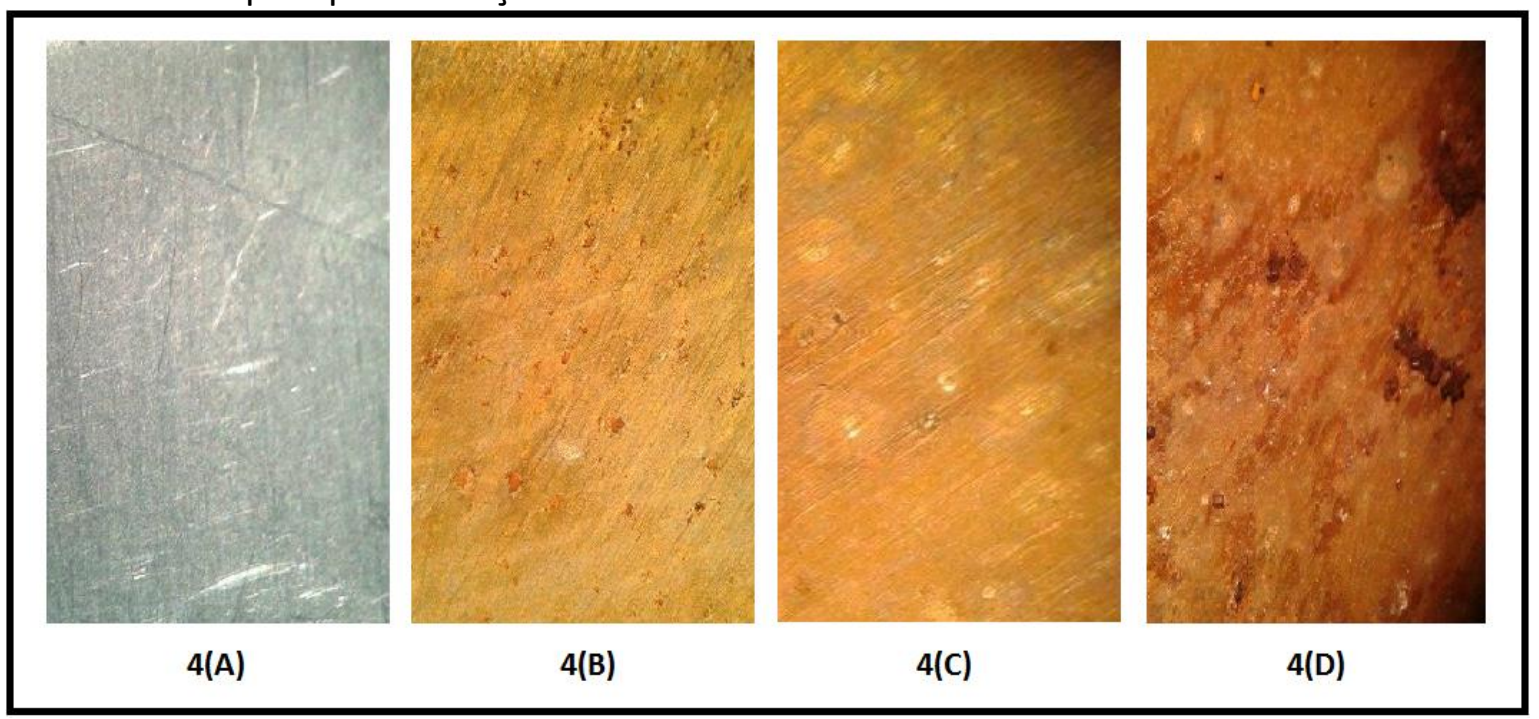

(A) Aço inoxidável ABNT 304. (B) Aço inoxidável ABNT 304 em solução de $\mathrm{HCl}$ a $4 \mathrm{~mol} \mathrm{~L}^{-1}$. (C) Aço inoxidável ABNT 304 em solução de $\mathrm{HCl}$ a $4 \mathrm{~mol} \mathrm{~L}^{-1}$ na presença do inibidor benzotriazol. (D) Aço inoxidável ABNT 304 em solução de $\mathrm{HCl}$ a 4 $\mathrm{mol} \mathrm{L}^{-1}$ na presença do inibidor nitrato de sódio. Fonte: Próprio autor

É possível observar que nas placas (B), (C) e (D) há presença de pontos de corrosão, inclusive com alteração de coloração. $\mathrm{Na}$
Figura (C), observa-se uma pequena inibição devido a presença do benzotriazol. Na Figura (D) é possível observar um maior grau de 
corrosão em função da maior quantidade de pontos corrosivos na mesma área seccionada.

\subsection{Potencial de Circuito Aberto}

$\mathrm{Na}$ Figura 2, são apresentados os resultados obtidos do potencial de circuito aberto, para o sistema na ausência e presença dos inibidores benzotriazol e nitrato de sódio.

Figura 2. Curva de Potencial de circuito aberto do aço inoxidável ABNT 304 em meio de $\mathrm{HCl}$ $4 \mathrm{~mol} \mathrm{~L}^{-1}$ na ausência e presença dos inibidores benzotriazol e nitrato de sódio

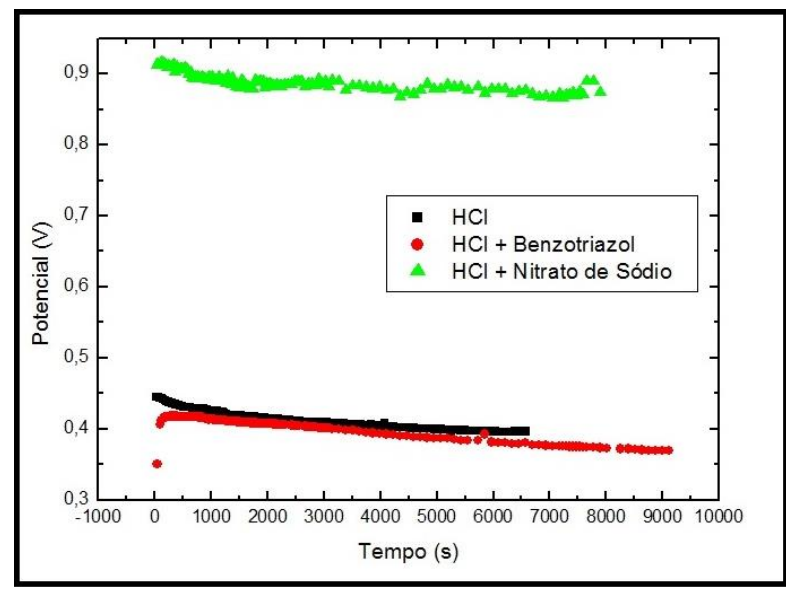

Fonte: Próprio autor.

Pelos resultados obtidos no gráfico de potencial em função do tempo (Figura 2), observa-se que comportamento dos potenciais do $\mathrm{HCl}$ e $\mathrm{HCl}$ + benzotriazol foram semelhantes, apresentando pequenas com alterações nos valores de potencial ao longo do tempo. Entretanto, a solução de $\mathrm{HCl}+$ nitrato de sódio, elevou o potencial de corrosão para valores mais nobres em função da alta capacidade oxidativa do nitrato de sódio na presença do ácido clorídrico. Estes dados corroboram para o observado pelas imagens óticas.

\subsection{Curva de Polarização}

Os gráficos obtidos da curva de polarização das placas de aço com potenciais de 0,40V e 0,45V são apresentados nas Figuras 3 , 4 e 5 .
Figura 3. Curva de polarização, região ativa e passiva do aço inoxidável ABNT 304 em meio a $\mathrm{HCl} 4 \mathrm{~mol} \mathrm{~L}^{-1}$, com potencias de $0,40 \mathrm{~V}$ e $0,45 \mathrm{~V}$, na ausência dos inibidores

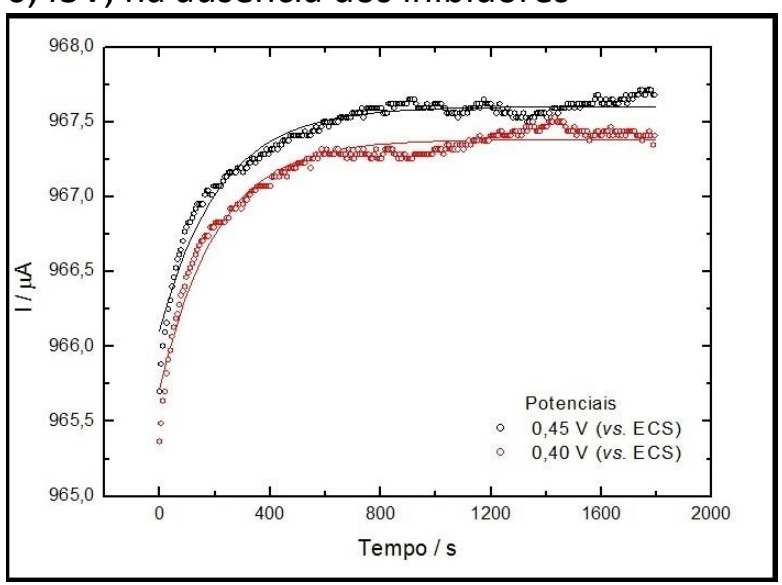

Fonte: Próprio autor.

Observa-se na Figura 3, que o aço inoxidável ABNT 304 não sofreu a corrosão até $967,5 \mu \mathrm{A}(0,45 \mathrm{~V})$ e $967,25 \mu \mathrm{A}(0,40 \mathrm{~V})$. Com o passar do tempo há o surgimento de pequenas variações nos valores da corrente, o que indica a presença de corrosão no meio.

Figura 4. Curva de polarização, região ativa e passiva do aço inoxidável ABNT 304 em meio a $\mathrm{HCl} 4 \mathrm{~mol} \mathrm{~L}^{-1}$, com potencial de $0,45 \mathrm{~V}$, na presença do inibidor benzotriazol

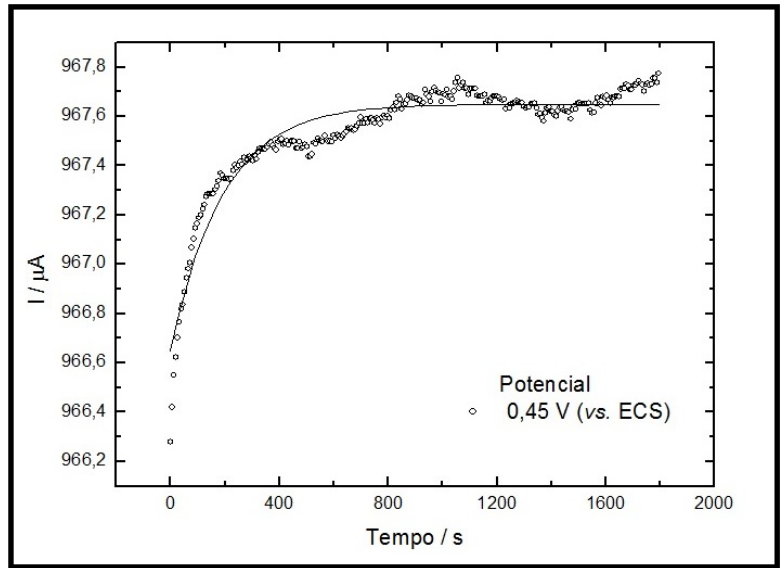

Fonte: Próprio autor.

Na Figura 4 até o valor de 967,4 $\mu \mathrm{A}$ $(0,45 \mathrm{~V})$ o comportamento é semelhante ao da curva da Figura 3, porém as variações de corrente ocorridas foram menores, indicando uma ação inibidora por parte do benzotriazol. 
Figura 5. Curva de polarização, região ativa e passiva do aço inoxidável ABNT 304 em meio a $\mathrm{HCl} 4 \mathrm{~mol} \mathrm{~L}^{-1}$, com potencial de $0,40 \mathrm{~V}$ e $0,45 \mathrm{~V}$, na presença do inibidor nitrato de sódio

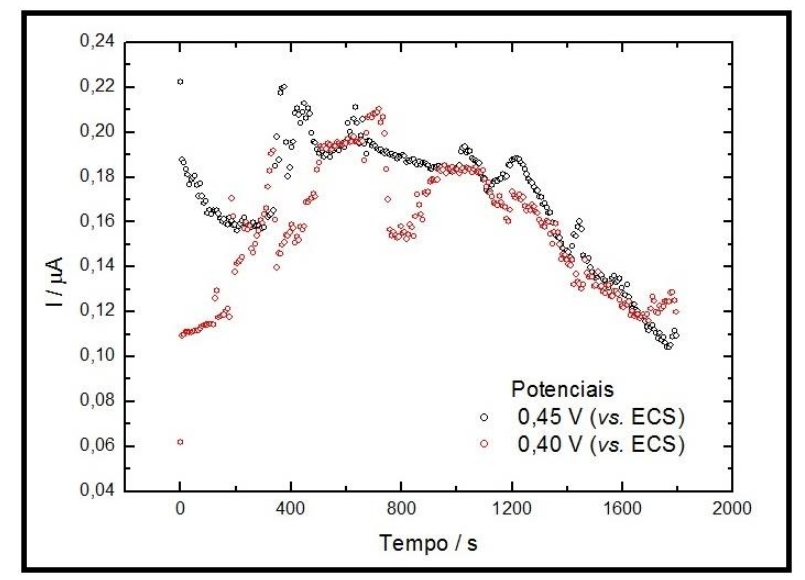

Fonte: Próprio autor.

Na Figura 5, observa-se pelo gráfico obtido um comportamento diferente das soluções anteriores. Visualmente, observouse que a solução corroeu completamente a placa. Sendo assim, o nitrato de sódio agiu como catalisador, e não como inibidor do aço inoxidável ABNT 304.

Tussolini e colaboradores (2007) em estudos do efeito eletroquímico do benzotriazol na presença de ácido sulfúrico 4,5 $\mathrm{molL}^{-1}$ observou que o mesmo não apresentou inibição de corrosão no aço inoxidável $A B N T$ 304. Diante desse resultado obtido, foi feita uma mistura de benzotriazol e benzimidazol. A mistura foi submetida a presença de ácido sulfúrico 4,5 molL ${ }^{-1}$ apresentando um percentual de inibição de $46 \%$.

\section{CONSIDERAÇÕES FINAIS}

É possível concluir que o benzotriazol, na concentração $10^{-2} \mathrm{~mol} \mathrm{~L}^{-1}$, mostra um efeito inibidor pouco representativo para o aço inoxidável ABNT 304 em meio de ácido clorídrico $4 \mathrm{~mol} \mathrm{~L}^{-1}$. Por outro lado, o nitrato de sódio, na concentração $10^{-2} \mathrm{~mol} \mathrm{~L}^{-1}$, atua como catalisador de oxidação do aço ABNT 304 em meio de ácido clorídrico $4 \mathrm{~mol} \mathrm{~L}^{-1}$, uma vez que as placas se mostraram completamente corroídas na sua presença.

\section{REFERÊNCIAS}

CHIVERINI, V. Aços e ferros fundidos. 7. ed. São Paulo: Associação Brasileira de Metais, 1996.

GENTIL, V. Corrosão. 4. ed. Rio de Janeiro: Livros Técnicos e Científicos, 2003.

SANTOS, T. F. A. Atrito interno em aços inoxidáveis austeníticos contendo martensita induzida por deformação. 2007. 96f. Dissertação (Mestrado em Engenharia de Materiais) Universidade Federal de Ouro Preto, Ouro Preto, 2007.

SIMÕES, M. S.; CASTRO, A. L. R.; ANDRADE, M. S. Atrito interno em aços inoxidáveis austeníticos contendo cobre. Revista Escola de Minas, v. 63, n.1, p.51-55, 2010. https://doi.org/10.1590/S0370$\underline{44672010000100009}$

TUSSOLINI, M. et al. Estudo do comportamento eletroquímico do benzotriazol e benzimidazol na oxidação do aço inoxidável tipo ABNT 304. Revista Escola de Minas, v. 60, n. 1, p. 41-44, $2007 . \quad$ https://doi.org/10.1590/S0370$\underline{44672007000100006}$

VIOMAR, A. et al. Comportamento eletroquímico da cisteína e do difosfonato para o aço inoxidável $304 \mathrm{em} \mathrm{HCl} 1 \mathrm{~mol} \mathrm{~L}^{-1}$. Revista Escola de Minas, v. 63, n.1, p.83-86, 2010. https://doi.org/10.1590/S0370$\underline{44672010000100014}$ 